\title{
Novel Method of Estimating Volume of Distribution of a Drug Obeying Michaelis-Menten Elimination Kinetics $^{1}$
}

\author{
Yi-Jong Lin, ${ }^{2,3}$ Donald J. Weidler, ${ }^{4}$ Dyal C. Garg, ${ }^{3}$ and John G. Wagner ${ }^{3,5}$
}

Received September 12, 1977-Final December 7, 1977

\begin{abstract}
The novel method of estimating the volume of distribution involves (a) administering an appropriate bolus intravenous dose of the drug, $(b)$ starting a constant-rate intravenous infusion of the drug at the same time, $(c)$ maintaining the infusion for a given number of hours, $(d)$ measuring the drug concentration over the entire time course, $(e)$ computer-fiting the postinfusion data to obtain estimates of $\mathrm{V}_{\mathrm{m}}$ and $\mathrm{K}_{\mathrm{m}}$, $(f)$ estimating the total area under the concentration-time curve from zero time to infinity, and $(g)$ iteratively solving a cubic equation to obtain the estimate of the volume of distribution. The method was applied to ethanol in the cat and yielded an average value of $635 \mathrm{ml} / \mathrm{kg}(63.5 \%$ of body weight) with a coefficient of variation of $23.0 \%$. This is equivalent to total body water in the cat.
\end{abstract}

KEY WORDS: ethanol; volume of distribution; Michaelis-Menten elimination kinetics.

\section{INTRODUCTION}

The volume of distribution of a drug is an essential parameter in many pharmacokinetic calculations, and it may or may not have physiological implications. This article describes a novel method of estimating the volume of distribution of a drug which obeys Michaelis-Menten elimination kinetics. The experimental procedure involves the administration of a

\footnotetext{
${ }^{1}$ Work performed in the Upjohn Center for Clinical Pharmacology, The Univeristy of Michigan Medical School, Ann Arbor, Michigan 48109.

${ }^{2}$ Present address: School of Pharmacy, University of Missouri, Kansas City, Missouri 64110.

${ }^{3}$ College of Pharmacy, The University of Michigan, Ann Arbor, Michigan 48109.

${ }^{4}$ Department of Internal Medicine, School of Medicine, The University of Michigan, Ann Arbor, Michigan 48109.

${ }^{5}$ Address correspondence to Dr. John G. Wagner, Upjohn Center for Clinical Pharmacology, The University of Michigan Medical Center, Ann Arbor, MI 48109.
} 
bolus intravenous dose of the drug and the initiation of a constant-rate intravenous infusion of the drug at the same time. The infusion is maintained over a period of $T$ hours. The drug concentration in blood is measured as a function of time from zero (time of the bolus dose and initiation of the infusion) until a period of time after $T$ hours when the drug has, for all practical purposes, disappeared from the blood. The total area under the concentration-time curve from zero to infinite time $\left(A_{\infty}\right)$ is estimated as well as the concentration at time zero $\left(C_{0}\right)$. The concentration at time $T\left(C_{T}\right)$ is an observed value. The postinfusion data are fitted to the integrated form of the Michaelis-Menten equation via computer to obtain estimates of $V_{m}$ and $K_{m}$. A cubic equation involving the volume of distribution (V), $A_{\infty}, C_{0}, C_{T}, V_{m}, K_{m}$, and $T$ is then solved iteratively via digital computer to obtain the estimate of $V$. The method was applied to ethanol in the cat, where $C$ refers to the whole blood concentration of ethanol $(\mathrm{mg} / \mathrm{ml})$.

\section{EXPERIMENTAL}

The cat experiments were run as described by Wagner et al. (1). During each study, blood pressure, heart rate, body temperature, respiratory rate, blood alcohol concentration, and blood acetaldehyde concentration were measured as a function of time, but only the blood alcohol

Table I. Experimental Conditions for Cat Studies

\begin{tabular}{|c|c|c|c|c|c|c|c|}
\hline \multirow[b]{2}{*}{$\begin{array}{l}\text { Cat } \\
\text { No. }\end{array}$} & \multirow[b]{2}{*}{$\begin{array}{l}\text { Study } \\
\text { No. }\end{array}$} & \multirow[b]{2}{*}{$\begin{array}{l}\text { Date of } \\
\text { study }\end{array}$} & \multirow[b]{2}{*}{$\begin{array}{l}\text { Weight } \\
(\mathrm{kg})\end{array}$} & \multirow[b]{2}{*}{$\begin{array}{l}\text { Loading dose } \\
\text { (ml 95\% } \\
\text { alcohol) }\end{array}$} & \multirow[b]{2}{*}{$\begin{array}{l}\text { Infusion rate }{ }^{a} \\
{[\mathrm{mg} /(\mathrm{kg} \times \mathrm{hr})]}\end{array}$} & \multicolumn{2}{|c|}{ Other drug } \\
\hline & & & & & & Drug & $\begin{array}{c}\text { Dose }^{b} \\
(\mathrm{mg} / \mathrm{kg})\end{array}$ \\
\hline \multirow{4}{*}{1} & $(16$ & $4 / 9 / 76$ & 4.0 & 2.5 & 125 & None & \\
\hline & 17 & $4 / 12 / 76$ & 4.0 & 1.9 & 110 & None & \\
\hline & 18 & $4 / 20 / 76$ & 4.0 & 1.9 & 110 & None & \\
\hline & 19 & $4 / 27 / 76$ & 4.0 & 2.5 & 125 & None & \\
\hline 2 & 20 & $5 / 27 / 76$ & 3.4 & 1.4 & 125 & None & \\
\hline 3 & 22 & $6 / 9 / 76$ & 3.15 & 1.3 & 125 & None & \\
\hline 4 & 25 & $7 / 8 / 76$ & 2.7 & 1.12 & 125 & None & \\
\hline 5 & 27 & $7 / 14 / 76$ & 3.5 & 1.44 & 125 & None & \\
\hline 2 & 21 & $5 / 28 / 76$ & 3.4 & 1.4 & 125 & Pentobarbital & 12.5 \\
\hline 3 & 23 & $6 / 10 / 76$ & 3.15 & 1.3 & 125 & Digoxin & 0.0286 \\
\hline 4 & 26 & $7 / 9 / 76$ & 2.7 & 1.12 & 125 & $\begin{array}{l}\text { atropine } \\
\text { sulfate }\end{array}$ & 0.04 \\
\hline 5 & 28 & $7 / 15 / 76$ & 3.5 & 1.44 & 125 & $\begin{array}{l}\text { Isproterenol } \\
\mathrm{HCl}\end{array}$ & 0.001 \\
\hline
\end{tabular}

${ }^{a}$ Infusion continued for $4 \mathrm{hr}$ in each experiment.

${ }^{b}$ Dose administered as a bolus intravenously at $4 \mathrm{hr}$. 
concentrations are reported herein. Body temperature was maintained constant at $100-101^{\circ} \mathrm{F}$ (rectal) during each experiment. Table I lists the study conditions for 12 studies in five different cats. In eight of the studies in the five cats, ethanol was the only drug involved (studies 16-19, 20,22, 25 , and 27). In four of the cats, ethanol was given only on 1 day and on the next day the same type of experiment was run with alcohol, but just as the infusion of ethanol ended a bolus intravenous dose of another drug was administered (see cat 2, studies 20 and 21; cat 3, studies 22 and 23; cat 4, studies 25 and 26; cat 5, studies 27 and 28). Ethanol and acetaldehyde were measured in whole arterial blood by the head-space, gas chromatographic method described by Wagner et al. (1).

\section{THEORETICAL}

Assuming that the "body" acts as a single compartment, equations 1 and 2 are applicable to the experimental conditions in the interval $0 \leq t \leq T$.

$$
\begin{gathered}
d C / d t=k_{0} / V-\left(V_{m} C\right) /\left(K_{m}+C\right) \\
C_{0}=D_{L} / V
\end{gathered}
$$

where $C$ is the whole blood concentration of ethanol $(\mathrm{mg} / \mathrm{ml}), t$ is time (hr), $V$ is the volume of distribution $(\mathrm{ml} / \mathrm{kg}), k_{0}$ is the constant infusion rate $[\mathrm{mg} /(\mathrm{kg} \times \mathrm{hr})], V_{m}$ is the maximal velocity of elimination $[\mathrm{mg} /(\mathrm{ml} \times$ $\mathrm{hr})$ ], $K_{m}$ is the Michaelis constant $(\mathrm{mg} / \mathrm{ml}), C_{0}$ is the estimated initial concentration of ethanol at time zero $(\mathrm{mg} / \mathrm{ml})$, and $D_{L}$ is the loading dose of ethanol given by bolus intravenous injection $(\mathrm{mg} / \mathrm{kg})$. To estimate $C_{0}$, the value of $600 \mathrm{ml} / \mathrm{kg}$ was used for $V$; this does introduce a small error into the final estimate of $V$ derived from the cubic equation derived later, but the error is very small.

After the infusion ceases at time $T$ (i.e., for $t \geq T$ ), the blood alcohol concentration obeys

$$
d C / d t=-\left(V_{m} C\right) /\left(K_{m}+C\right)
$$

Integration of equation 1 yields

$$
\begin{aligned}
t= & \left.V K_{m} /\left(k_{0}-V_{m} V\right) \ln \left[\left\{\left(k_{0}-V_{m} V\right) C+k_{0} K_{m}\right\} /\left\{k_{0}-V_{m} V\right) C_{0}+k_{0} K_{m}\right\}\right] \\
& +\left\{V /\left(k_{0}-V_{m} V\right)\right\}\left(C-C_{0}\right)-\left\{k_{0} K_{m} V /\left(k_{0}-V_{m} V\right)^{2}\right\} \\
& \times \ln \left[\left\{\left(k_{0}-V_{m} V\right) C+k_{0} K_{m}\right\} /\left\{\left(k_{0}-V_{m} V\right) C_{0}+k_{0} K_{m}\right\}\right]
\end{aligned}
$$


Integration of equation 4, to obtain the area under the concentrationtime curve from 0 to $T$, yields equation 5 , where $C_{T}$ is the concentration at time $T$ :

$$
\begin{aligned}
\text { AUC 0-T }= & \int_{0}^{T} C(t) d t=\int_{C_{T}}^{C_{0}} t(C) d t+C_{T} T \\
= & \left\{V /\left(k_{0}-V_{m} V\right\}\left[-C_{T}^{2} / 2-C_{0}^{2} / 2+C_{0} C_{T}\right.\right. \\
& +K_{m}\left\{k_{0} K_{m} /\left(k_{0}-V_{m} V\right)+C_{T}\right\} \ln \left\{\left(k_{0}-V_{m} V\right) C_{0}+k_{0} K_{m}\right\} \\
& +K_{m}\left(C_{T}-C_{0}\right)-K_{m}\left\{\left(\left(k_{0}-V_{m} V\right) C_{T}+k_{0} K_{m}\right) /\left(k_{0}-V_{m} V\right)\right\} \\
& \left.\times \ln \left\{\left(k_{0}-V_{m} V\right) C_{T}+k_{0} K_{m}\right\}\right]-\left\{k_{0} K_{m} V /\left(k_{0}-V_{m} V\right)^{2}\right\} \\
& \times\left[\left\{k_{0} K_{m} /\left(k_{0}-V_{m} V\right)+C_{T}\right\} \ln \left\{\left(k_{0}-V_{m} V\right) C_{0}+k_{0} K_{m}\right\}\right. \\
& +C_{T}-C_{0}-\left\{\left(k_{0}-V_{m} V\right) C_{T}+k_{0} K_{m}\right\} /\left(k_{0}-V_{m} V\right) \\
& \left.\times \ln \left\{\left(k_{0}-V_{m} V\right) C_{T}+k_{0} K_{m}\right\}\right]+C_{T} T
\end{aligned}
$$

Integration of equation 3 , to obtain the area under the concentrationtime curve from $T$ to $\infty$, yields

$$
\text { AUC } T-\infty=C_{T} / V_{m}\left[C_{T} / 2+K_{m}\right]
$$

Addition of equations 5 and 6 yields the total area, $A_{\infty}$. Rearrangement of the resulting equation for $A_{\infty}$ yields

$$
A V^{3}+B V^{2}+C^{\prime} V+D+\left\{E V^{3}+F V^{2}\right\} \ln [(G-H V) /(I-J V)]=0
$$

where

$$
\begin{aligned}
A= & V_{m}^{2}\left[A_{\infty} V_{m}-C_{T}^{2}-C_{0}^{2} / 2+C_{0} C_{T}\right. \\
& \left.+K_{m} C_{T}-K_{m} C_{0}-V_{m} C_{T} T-C_{T} K_{m}\right] \\
B= & k_{0} V_{m}\left[3 K_{m} C_{T}+(5 / 2) C_{T}^{2}+3 V_{m} C_{T} T\right. \\
& \left.+K_{m} C_{0}-K_{m} C_{T}-2 C_{0} C_{T}+C_{0}^{2}-3 A_{\infty} V_{m}\right] \\
C^{\prime}= & k_{0}^{2}\left[3 A_{\infty} V_{m}-2 C_{T}^{2}-C_{0}^{2} / 2+C_{0} C_{T}-3 V_{m} C_{T} T-3 C_{T} K_{m}\right] \\
D= & \left(k_{0}^{3} / V_{m}\right)\left[C_{T}^{2} / 2+C_{T} K_{m}+V_{m} C_{T} T-A_{\infty} V_{m}\right] \\
E= & K_{m} V_{m}^{2} C_{T} \\
F= & -\left[k_{0} K_{m}^{2} V_{m}+k_{0} V_{m} K_{m} C_{T}\right] \\
G= & k_{0} C_{0}+k_{0} K_{m} \\
H= & V_{m} C_{0}
\end{aligned}
$$




$$
\begin{aligned}
& I=k_{0} C_{T}+k_{0} K_{m} \\
& J=V_{m} C_{T}
\end{aligned}
$$

Since the parameters $C_{0}, k_{0}, C_{T}, T, V_{m}, K_{m}$, and $A_{\infty}$ are readily estimated or known from experimental data, $V$ may be obtained from equations 7-17. An iterative digital computer program (given in the Appendix) was employed to obtain $V$. The program includes equations 8-17.

To obtain estimates of $V_{m}$ and $K_{m}$, the postinfusion $C, t$ data were fitted to the integrated form of equation 3 , namely equation 18 , by numerical integration of equation 3, using the program NONLIN (2) and the AMDAHL 470V/6 digital computer. Details of such fittings with ethanol data are given elsewhere (3-7). In equation $18, C_{T}$ is the estimated value of the blood alcohol concentration at cessation of the infusion and the other symbols have already been defined.

$$
C_{T}-C+K_{m} \ln \left[C_{T} / C\right]=V_{m}(t-T)
$$

\section{RESULTS}

The estimated initial and the observed ethanol concentrations are listed in Table II. The sensitivity of the assay was such that essentially the total area under the concentration-time curve was obtained by application of the trapezoidal rule. This was checked by using equation 6 as well as the trapezoidal rule to estimate AUC $T-\infty$, where for the trapezoidal rule only the concentration up to the last sampling time (Table II) was employed. For the 12 sets of data the means were 0.834 and $0.824 \mathrm{mg} /(\mathrm{ml} \times \mathrm{hr})$ (paired $t=0.37, p>0.25$ ) for the area from equation 6 and by trapezoidal rule, respectively. This also provides a check on the pharmacokinetic model.

Table III lists the estimated values of $V_{m}, K_{m}$, and $A_{\infty}$ as well as the estimated values of $V$, obtained via computer with equations 7-17.

\section{DISCUSSION}

For cat 1 , studied four times with ethanol alone, the mean volume of distribution was $571 \mathrm{ml} / \mathrm{kg}$, with a coefficient of variation of $7 \cdot 4 \%$. In calculating the other means, this mean of $571 \mathrm{ml} / \mathrm{kg}$ was employed to represent cat 1 . For the five cats given ethanol alone, the mean volume of distribution was $635 \mathrm{ml} / \mathrm{kg}$, with a coefficient of variation of $23.0 \%$. For the experiments in cats $2-5$, where another drug was given by bolus intravenous injection at $4 \mathrm{hr}$, the mean volume of distribution was 


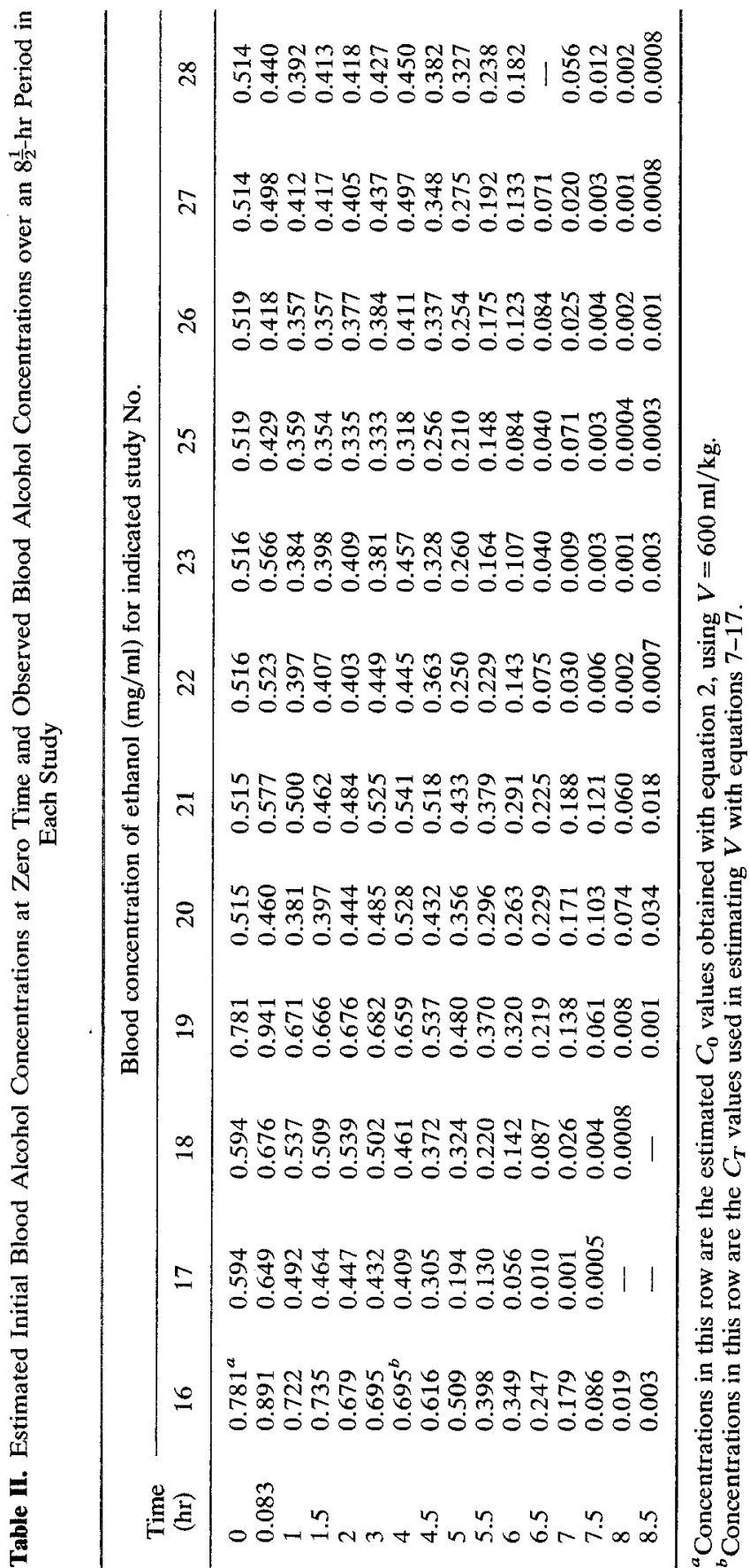


Table III. Trapezoidal Areas, $A_{\infty}$, and Estimated Values of $V_{m}, K_{m}$, and $V$

\begin{tabular}{|c|c|c|c|c|c|}
\hline $\begin{array}{l}\text { Cat } \\
\text { No. }\end{array}$ & $\begin{array}{l}\text { Study } \\
\text { No. }\end{array}$ & $\begin{array}{c}V_{m} \\
{[\mathrm{mg} /(\mathrm{ml} \times \mathrm{hr})]}\end{array}$ & $\begin{array}{c}K_{m} \\
(\mathrm{mg} / \mathrm{ml})\end{array}$ & $\begin{array}{c}A_{\infty} \\
{[\mathrm{mg} /(\mathrm{ml} \times \mathrm{hr})]}\end{array}$ & $\begin{array}{c}V \\
(\mathrm{ml} / \mathrm{mg})\end{array}$ \\
\hline \multirow{4}{*}{1} & 16 & 0.210 & 0.0603 & 4.25 & $609) \approx$ \\
\hline & 17 & 0.259 & 0.0813 & 2.33 & $535 \ln r$ \\
\hline & 18 & 0.172 & 0.0294 & 2.82 & 534 \\
\hline & 19 & 0.193 & 0.0414 & 4.10 & $607) \bar{Q}$ \\
\hline 2 & 20 & 0.138 & 0.0772 & 2.90 & $876 \Sigma$ \\
\hline 3 & 22 & 0.176 & 0.0579 & 2.40 & 633 \\
\hline 4 & 25 & 0.210 & 0.125 & 1.90 & 614 \\
\hline \multirow[t]{2}{*}{5} & 27 & 0.250 & 0.129 & 2.40 & 483 \\
\hline & & & & $\begin{array}{r}\text { Mean } \\
\text { C.V. }(\%)\end{array}$ & $\begin{array}{l}635 \\
23.0\end{array}$ \\
\hline 2 & 21 & 0.165 & 0.0634 & 3.30 & 799 \\
\hline 3 & 23 & 0.211 & 0.0505 & 2.26 & 538 \\
\hline 4 & 26 & 0.216 & 0.111 & 2.12 & 550 \\
\hline \multirow[t]{3}{*}{5} & 28 & 0.159 & 0.0370 & 2.50 & 724 \\
\hline & & & & $\begin{array}{r}\text { Mean } \\
\text { C.V. }(\%)\end{array}$ & $\begin{array}{l}653 \\
19.8\end{array}$ \\
\hline & & & & $\begin{array}{r}\text { Grand mean } \\
\text { C.V. }(\%)\end{array}$ & $\begin{array}{l}643 \\
20.3\end{array}$ \\
\hline
\end{tabular}

$653 \mathrm{ml} / \mathrm{kg}$, with a coefficient of variation of $19.8 \%$; when these same cats received ethanol alone, the mean volume of distribution was $652 \mathrm{ml} / \mathrm{kg}$, with a coefficient of variation of $25.5 \%$ (paired $t=0.016, p>0.25$ ). Hence there was no real evidence that the other drugs administered altered the volume of distribution of ethanol. However, the experimental design was not a good test of alteration of the volume of distribution of ethanol by another drug. If the alcohol infusion had been continued beyond the time of injection of the second drug, as in the studies of Wagner et al. (1), the design would have been better to test such an effect.

Table IV lists estimates of total body water in the adult cat taken from Altman and Dittmer (8). The weighted mean total body water is $593 \mathrm{ml} / \mathrm{kg}$, and the mean value for 11 cats, based on the urea method, is $630 \mathrm{ml} / \mathrm{kg}$. These values agree very closely with the volume of distribution of ethanol estimated in our studies (Table III), strongly suggesting (a) that ethanol is distributed in total body water as has been reported before $(9,10)$ and (b) that the method described herein, using ethanol, may be a useful method for determining total body water.

The volume of distribution estimated in such studies by the method outlined is not necessarily just the " $V_{d}$ of the one-compartment open model." Under the conditions of the studies, various body 
Table IV. Estimates of Total Body Water in Adult Cats (8)

\begin{tabular}{ccl}
$\begin{array}{c}\text { No. } \\
\text { animals }\end{array}$ & $\begin{array}{c}\text { Total } \\
\text { body water } \\
(\mathrm{ml} / \mathrm{kg})\end{array}$ & \multicolumn{1}{c}{ Method } \\
\hline 1 & 666 & Desiccation \\
1 & 580 & Desiccation \\
3 & 677 & Desiccation \\
1 & 615 & Deuterium oxide \\
8 & 500 & Sodium chloride \\
11 & 630 & Urea \\
Weighted mean & 593 & \\
\hline
\end{tabular}

"compartments" are essentially "filled" with drug within about a 1-hr period after administration of the bolus intravenous dose and the initiation of the constant-rate intravenous infusion. Hence a multicompartment open model essentially becomes a one-compartment open model within a short time after initiation of the experiment. The fact that there was little, if any, evidence of a distribution phase in the postinfusion data supports this. A similar but linear pharmacokinetic example, with a drug having an apparent elimination half-life of $11.5 \mathrm{hr}$, was reported by Paalman et al. (11); when an infusion of their drug was administered over $0.5 \mathrm{hr}$, the postinfusion data were fitted by a biexponential equation, but when the same drug was infused over a $24-\mathrm{hr}$ period the postinfusion data were fitted with only a single exponential term. Unfortunately, in that article (11) the captions for Figs. 2 and 3 were reversed.

Table V. Results of Tests for Steady-State Alcohol Levels

\begin{tabular}{|c|c|c|c|c|c|c|c|c|}
\hline $\begin{array}{l}\text { Cat } \\
\text { No. }\end{array}$ & $\begin{array}{l}\text { Study } \\
\text { No. }\end{array}$ & $\begin{array}{l}\text { Time } \\
\text { period } \\
\text { (hr) }\end{array}$ & $N^{a}$ & $\begin{array}{c}\text { Slope of } C, t \\
\text { plot }\end{array}$ & $t^{b}$ & $p$ value & $\begin{array}{l}\text { Mean } C \\
(\mathrm{mg} / \mathrm{ml})\end{array}$ & $\begin{array}{l}\text { C.V. } \\
(\%)\end{array}$ \\
\hline \multirow{4}{*}{1} & 16 & $1-4$ & 5 & -0.0107 & 1.19 & $p>0.10$ & 0.705 & 3.2 \\
\hline & 17 & $1-4$ & 5 & -0.0254 & 6.98 & $0.01>p>0.001$ & 0.449 & 7.0 \\
\hline & 18 & $1-4$ & 5 & -0.0227 & 2.94 & $0.10>p>0.05$ & 0.510 & 6.2 \\
\hline & 19 & $1-4$ & 5 & -0.00176 & 0.43 & $p>0.25$ & 0.671 & 1.3 \\
\hline 2 & 20 & $1.5-4$ & 4 & 0.0498 & 8.25 & $0.01>p>0.001$ & 0.464 & 12.1 \\
\hline 3 & 22 & $1-4$ & 5 & 0.0187 & 3.74 & $0.05>p>0.02$ & 0.420 & 5.9 \\
\hline 4 & 25 & $2-4$ & 3 & 0.00606 & 1.89 & $p>0.10$ & 0.329 & 2.8 \\
\hline 5 & 27 & $1-4$ & 5 & 0.0276 & 3.36 & $0.05>p>0.02$ & 0.434 & 8.6 \\
\hline 2 & 21 & $1.5-4$ & 4 & 0.0321 & 6.84 & $0.05>p>0.02$ & 0.503 & 7.2 \\
\hline 3 & 23 & $1-4$ & 5 & 0.0178 & 1.68 & $p>0.10$ & 0.406 & 7.6 \\
\hline 4 & 26 & $1-4$ & 5 & 0.01805 & 7.02 & $0.01>p>0.001$ & 0.377 & 5.9 \\
\hline 5 & 28 & $1-4$ & 5 & 0.01698 & 6.66 & $0.01>p>0.001$ & 0.420 & 5.0 \\
\hline
\end{tabular}

${ }^{a} N=$ number of concentration-time pairs (see Table II) used to estimate the slope of the $C, t$ plot.

${ }^{b} t=$ Absolute value of slope/standard error of slope. 
A test was made for attainment of steady-state alcohol blood levels in each of the 12 studies in the cats. The method employed was to test the significance of difference of the slope of the $C, t$ plot from zero by $t$ test in the expected steady-state period. Results are given in Table $V$. In five (studies 16, 18, 19, 23, and 25) the slope of the $C, t$ plot was not significantly different from zero, indicating attainment of steady state. Table $\mathrm{V}$ also lists the mean concentrations and their coefficients of variation calculated from the same concentration values as used to estimate the slopes. There was a strong correlation $(r=0.949, p<0.001)$ for the linear regression of these coefficients of variation vs. the absolute value of the slope. This suggests that the larger coefficients of variation were associated with lack of attainment of steady state and were not the result of error in the essay.

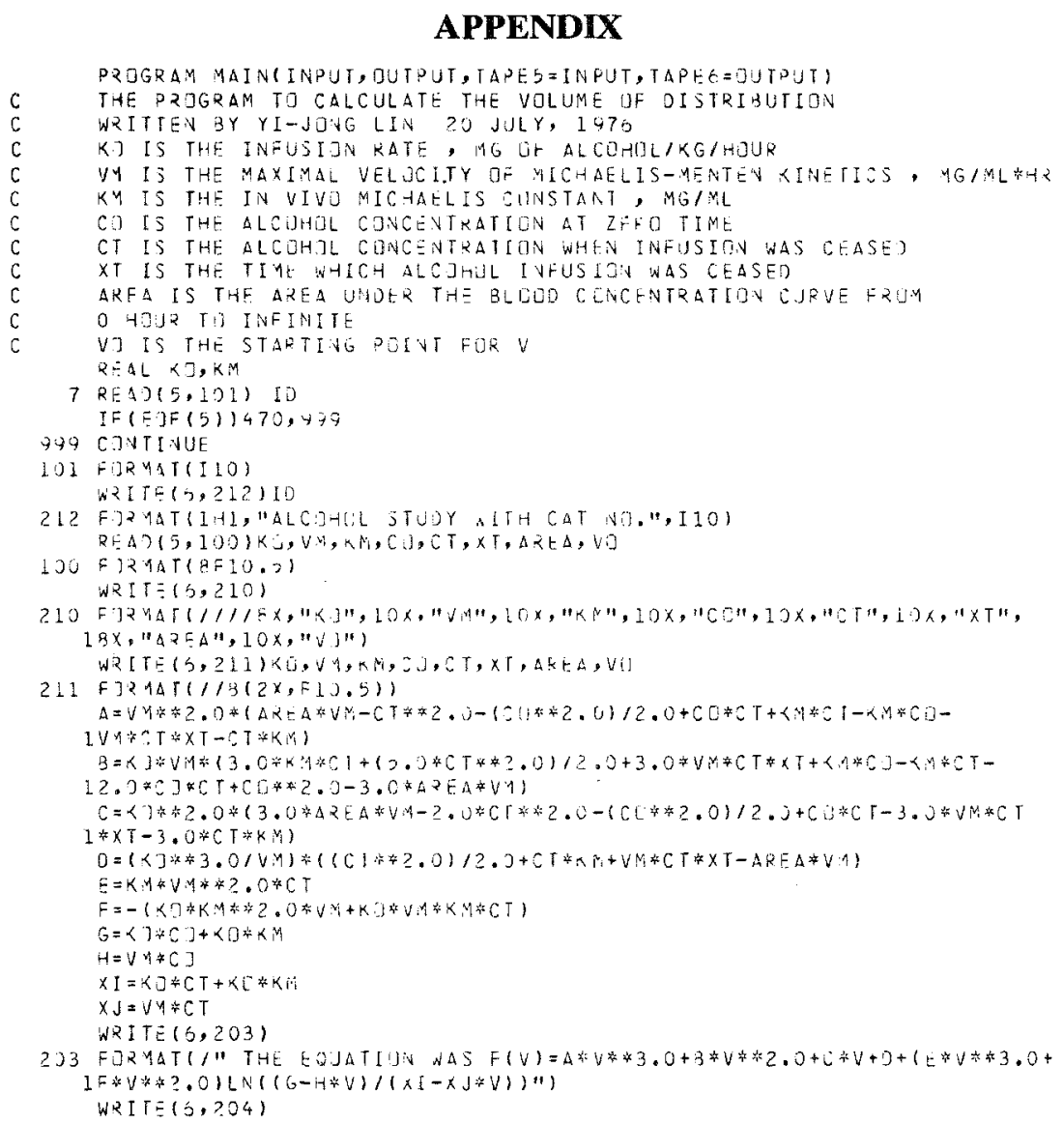




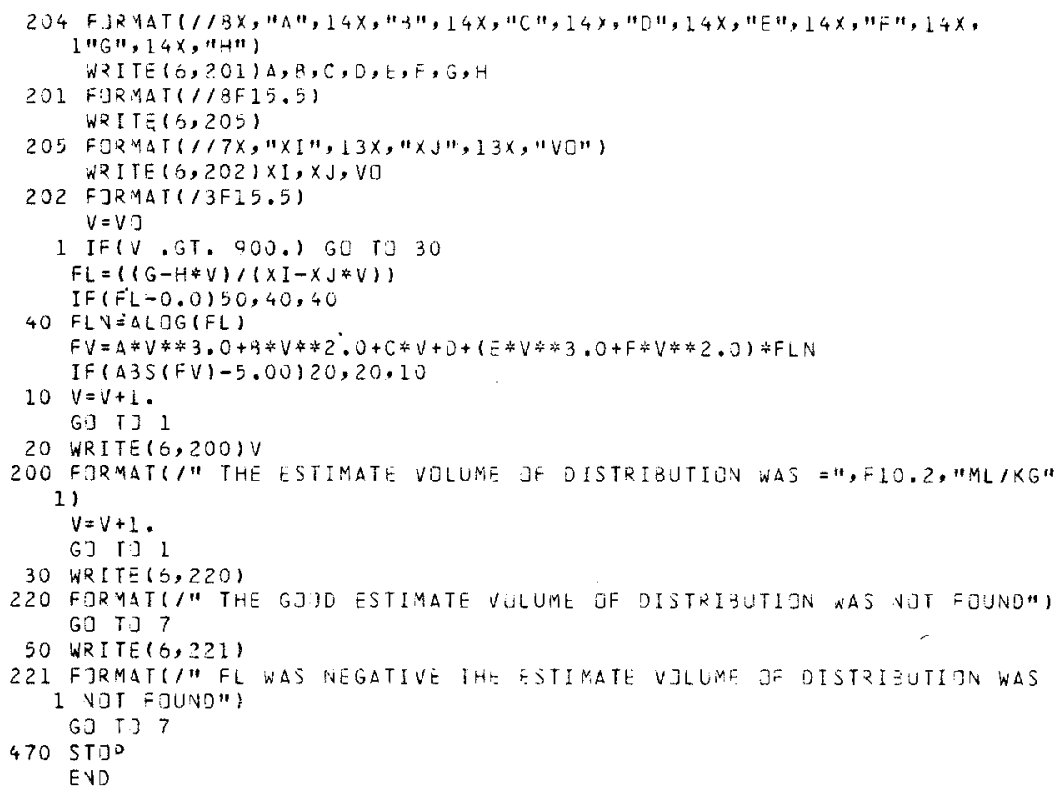

\section{REFERENCES}

1. J. G. Wagner, D. J. Weidler, and Y.-J. Lin. New method for detecting and quantitating pharmacokinetic drug-drug interactions applied to ethanol-propranolol. Res. Commun. Chem. Pathol. Pharmacol. 13:9-18 (1976)

2. C. M. Metzler. Biostatistical Technical Report 7292/69/7292/005, Upjohn Co., Kalamazoo, Mich., 1969.

3. J. G. Wagner, P. K. Wilkinson, A. J. Sedman, D. R. Kay, and D. J. Weidler. Elimination of alcohol from human blood. J. Pharm. Sci. 65:152-154 (1976).

4. P. K. Wilkinson, A. J. Sedman, E. Sakmar, R. H. Earhart, D. J. Weidler, and J. G. Wagner. Blood ethanol concentrations during and following constant rate intravenous infusion of alcohol. Clin. Pharmacol. Ther. 19:213-223 (1976).

5. Y.-J. Lin, D. J. Weidler, D. C. Garg, and J. G. Wagner. Effects of solid food on blood levels of alcohol in man. Res. Commun. Chem. Pathol. Pharmacol. 13:713-722 (1976).

6. A. J. Sedman, P. K. Wilkinson, E. Sakmar, D. J. Weidler, and J. G. Wagner. Food effects on absorption and metabolism of alcohol. J. Stud. Alcohol 37:1197-1214 (1976).

7. P. K. Wilkinson, A. J. Sedman, E. Sakmar, Y.-J. Lin, and J. G. Wagner. Fasting and nonfasting bloed ethanol concentrations following repeated oral administration of ethanol to one adult male subject. J. Pharmacokin. Biopharm. 5:41-52 (1977).

8. P. L. Altman and D. S. Dittmer (eds.). Blood and Other Body Fluids, Federation of American Societies for Experimental Biology, Bethesda, Md., Third Printing, 1971, p. 352.

9. R. B. Forney. General pharmacology of alcohol. Abstracts of symposia and contributed papers presented to the APhA Academy of Pharmaceutical Sciences at the 118th Annual Meeting of the American Pharmaceutical Association, San Francisco, California, March 27-April 2, Vol. 1, No. 1, 1971, p. 28. 
10. G. S. L. Pawon and W. H. Hoult. The determination of total body water in man by ethanol dilution. Biochem. J. 87:6P-7P (1963).

11. A. C. A. Paalman, J. Siebelink, J. C. Roos, and A. J. Dunning. Development of a dosage scheme for simultaneous intravenous and oral administration of mexiletine. Postgrad. Med. J. 53:128-134 (Suppl. 1) (1977). 